\title{
TENDÊNCIAS CURRICULARES NAS ESCOLAS DE FORMAÇÃO TÉCNICA PARA O SUS
}

\author{
CURRICULAR TRENDS IN THE SCHOOLS PROVIDING \\ TECHNICAL TRAINING FOR THE SUS
}

Isabel Brasil Pereira 1

Resumo Este artigo mapeia e analisa tendências curriculares das escolas de educação profissional em nível técnico para o Sistema Único de Saúde (SUS). Trata-se de, mediante resgate da literatura sobre currículo, analisar a organização, a seleção e a hierarquização de conhecimentos, fatores que estão articulados às lutas entre projetos educacionais. É significativo para o estudo o fato de que a educação profissional é chamada a responder às questões advindas do mundo do trabalho. Neste sentido, recuperam-se contradições existentes no campo educacional, como a idéia de que, por um lado, é verdade que 'a experiência ensina', consistindo em ponto significativo para a aprendizagem, mas que, por outro lado, é necessário fazer a crítica na fé incomensurável na experiência cotidiana como um processo que, por si só, garante a aprendizagem qualificada.

Palavras-chave educação profissional; trabalho na saúde; currículo.
Abstract This article outlines and analyses the curricular trends in the schools providing professional technical education for the Brazilian Health System's workers (Sistema Único de Saúde-SUS). With the help of a close survey of the literature on curricula, it analyses the organization, selection and hierarchical gradation of knowledge, all of which are connected with the struggle between educational projects. For the study, the fact that professional education is called to respond to the issues originating in the labour world is highly significant. In this sense, we attempted to rescue the contradictions existing in the educational field, such as, for instance, the idea that, even if it is true that "experience is the best teacher" and an important stage in the learning process, it is also important to criticize an exaggerated faith on the everyday experience and the presumption that experience can, by itself, provide qualified learning. Key words professional education; health work; curricula. 


\section{Introdução}

No cenário da Educação Profissional em Saúde, a discussão curricular emerge marcada por fatores como necessidade de adequação à legislação de ensino e demandas de maior articulação entre ensino e serviço. Numa abordagem crítica, trata-se de explicitar os conhecimentos que possibilitam ao trabalhador a reflexão e a ação na prática em saúde, sempre questionando o porquê da inclusão e da exclusão de determinados conhecimentos.

Com olhar histórico, observa-se que a reflexão acerca do conhecimento alimentou e justificou a querela relativa aos currículos, que marcou a educação a partir de determinado momento. Até que a perspectiva aristotélica fosse questionada, o conhecimento humano não apontava questões maiores, e o currículo era determinado pela tradição, que, por sua vez, apresentava relativa estabilidade quanto às concepções de ensino.

Porém, é o Iluminismo que colocará em xeque o ensino da tradição, ao questionar, principalmente, as verdades estabelecidas acerca do que é o homem e a razão. A partir daí, o conhecimento passa a ser entendido como objeto de uma análise não mais filosófica (e ética), mas científica, em que, não raro, as idéias de evolução, progresso e aperfeiçoamento detêm um papel operador fundamental:

\footnotetext{
“Reconhecendo a íntima associação entre poder e conhecimento, o século XVIII fez conviver duas posições diametralmente opostas, no que se refere às implicações educacionais. Por um lado, os iluministas insistem em imaginar um novo mundo onde, tal como queria Platão, conhecimento é virtude. Educar é, pois, difundir as Luzes que garantem, ao mesmo tempo, a autonomia da razão e o desenvolvimento ético da sociedade. Esta é a função a partir da qual concebem uma escola pública: difundir as luzes, criar o novo mundo sem injustiças e desigualdades e o novo cidadão que irá habitá-lo, em condições de gozar de sua nova liberdade e igualdade. Do outro lado, polêmico, Rousseau garante: o desenvolvimento das ciências e das artes não implica em progresso ético" (Valle, 1996)
}

Forte no século XIX, a influência do positivismo na relação entre educação e conhecimento, e, portanto, nos currículos escolares, requer que abarquemos em nosso estudo reflexões e conceitos já desvelados pela literatura da área. Ou seja, o positivismo como uma corrente filosófica que mantém, ainda hoje, uma forte presença na Sociologia e nas práticas sociais, como a educação profissional e a saúde. Para Lowy (1986), as origens do positivismo estão no Iluminismo, no século XVIII, quando Condorcet formula a idéia de que a ciência que estudasse a sociedade teria que ser uma "matemática social" e defende a neutralidade de todas as ciências, no sentido de que a elaboração e a reflexão deveriam ser livres de preconceitos e interesses ${ }^{2}$. 
Com base no ideário positivista, o funcionalismo, segundo Ramos (2001), é também presença marcante na construção dos currículos. O funcionalismo tem sua base no ideário positivista e tem como expoentes autores como Malinowski e Radcliffe-Brown, antropólogos ingleses, e, na sociologia americana, Merton e Passos ${ }^{3}$. Na concepção funcionalista, as sociedades são totalidades constituídas como organismos vivos, formadas por fatores que interagem e são interdependentes, sendo passíveis de reajustes. Neste sentido, cada sociedade tem mecanismos de controle para os fatos internos e externos que ameacem seu equilíbrio. Esses mecanismos fazem com que os 'desvios' tendam a ser desfeitos, produzindo uma integração, baseada no consenso de valores e de normas. Portanto, há um movimento funcional, mas que tende à adaptação.

Noutro sentido, afinado com o olhar progressista da educação, os currículos voltados à formação profissional em saúde não podem ser simples repartições, estanques e isoladas desta ou daquela área de conhecimento, resultando em práticas de ensino mecânicas, burocráticas, que trabalham pela simples repetição de fórmulas e esquemas vazios. Assim se perderia o processo dinâmico, o conhecimento crítico, as mediações entre as partes e o todo, a própria construção do conhecimento a partir do cotidiano. Para o pensamento crítico, trata-se de jamais confundir conhecimento com privilégio, com usos exclusivos e excludentes, e, sim, considerá-lo como um legado humano, que deve apontar, sempre, a emancipação de toda a humanidade.

O campo de currículo no Brasil emerge e se desenvolve sob influências nacionais e internacionais. Nas décadas de 1920 e 1930, sob a influência do ideário escolanovista que permeia as reformas educacionais ocorridas no Brasil nessa época, os 'pioneiros da educação nova' sentem necessidade de reformar e introduzir conteúdos e programas no sistema de ensino. Como Silva (2000) nos ajuda a entender:

“É interessante notar que tanto os modelos mais tecnocráticos, como os de Bobit e Tyler, quanto os modelos mais progressistas de currículo, como o de Dewey, que emergiram no século XX, nos Estados Unidos, constituíam, de uma certa forma, uma reação ao currículo clássico, humanista, que havia dominado a educação secundária desde sua institucionalização (...) O modelo tecnocrático destacava a abstração e a suposta inutilidade - para a vida moderna e para as atividades laborais - das habilidades e conhecimentos cultivados pelo currículo clássico (...) O modelo progressista, sobretudo aquele 'centrado na criança', atacava o currículo clássico por seu distanciamento dos interesses das experiências das crianças e dos jovens (...) E desconsiderava a psicologia infantil" (Silva, 2000, pp.26-27). 
Á medida que o Brasil também se moderniza, sobretudo na segunda metade do século XX, o impacto da divisão social do trabalho se estende aos currículos e às disciplinas exigidas de estudantes e trabalhadores. É certo que isso diz respeito, sobretudo, às linhas de frente do processo que dá forma ao capitalismo avançado (Wallerstein, 2001), deixando espaço para descompassos de vários tipos, que não cabe aqui analisar. Mas é notável como o conhecimento da tradição humanista, de 1970 em diante, vai sendo retirado dos currículos, ao lado da exigência de currículos apenas profissionalizantes para os trabalhadores, de modo que estes não pudessem ou precisassem ter acesso à universidade.

Em sua fase mais recente, a expansão do capitalismo, na forma de acumulação flexível e distribuição global de empregos e processos produtivos, é ainda mais hostil a uma educação crítica dos trabalhadores, situando suas exigências sempre no espaço da qualidade, do mito da qualidade total. Indicar que o mundo do trabalho é sempre afetado pelos processos e formas do capitalismo em expansão não implica, no entanto, fazer uma defesa essencialista da qualificação profissional, criando uma vinculação direta e não mediada entre a separação de saberes por campos disciplinares e a divisão social e técnica do trabalho. Isso posto, a constituição de disciplinas escolares, as subdivisões em seu interior, assim como aquilo que é privilegiado ou colocado em segundo plano se relaciona com disputas políticas no âmbito dos próprios campos de conhecimento, sem que isso esteja diretamente vinculado à divisão técnica e social do trabalho.

A década de 1970 foi cenário de transformação nas teorias educacionais, e, portanto, incidiu sobre as teorias curriculares, constituindo uma realidade da chamada Nova Sociologia da Educação, que apresentava como expoente, na Inglaterra, Michael Young. Currículos, nas palavras de Young (1971), "não podem ser percebidos como uma existência à parte dos homens que os criam, são sim invenções sociais, como as cidades ou partidos políti$\cos ^{\prime \prime}$ (p. 51). Não há, portanto, inocência possível diante da relação entre conhecimento, currículo e poder.

Nenhuma ideologia da neutralidade do conhecimento tem resposta para a divisão social do trabalho, que opõe o trabalho manual ao intelectual. Essa divisão atravessa o cotidiano das instituições de ensino de outros setores e as divisões do conhecimento em currículos de cursos de formação profissional.

Na composição dos paradigmas que constituíram a Nova Sociologia da Educação, com a formulação de teorias críticas educacionais, ressalta Silva (2000):

“Uma revisão brasileira não deixaria de assinalar o importante papel da obra de Paulo Freire, enquanto os franceses certamente não deixariam de destacar o pa- 
pel dos ensaios fundamentais de Althusser, Bourdieu e Passeron, Baudelot e Establet. Uma avaliação mais equilibrada argumentaria, entretanto, que o movimento de renovação da teoria educacional que iria abalar a teoria educacional tradicional, tendo influência não apenas teórica, mas inspirando verdadeiras revoluções nas próprias experiências educacionais, explodiu em vários locais do mundo ao mesmo tempo(..) As teorias críticas do currículo efetuam uam completa inversão nos fundamentos das teorias tradicionais " (Silva, 2000, p. 29).

Como enfatizam Moreira e Silva (1994), pode-se dizer que as teorias educacionais identificadas como críticas não entendem o currículo como área voltada apenas para questões pragmáticas, em torno de procedimentos e recursos técnicos, já se podendo falar agora em um pensamento crítico do currículo gerado por questões sociológicas, políticas, epistemológicas.

\section{Questões presentes nos currículos da Formação Profissional em Saúde}

As teorias sobre o currículo o consideram um projeto educacional planejado e desenvolvido a partir de uma seleção da cultura e das experiências das quais se deseja que as gerações participem. Acrescente-se que, no campo educacional, há uma luta por projetos, na qual estão em disputa entendimentos diversos sobre a relação entre escola, cultura, cidadania e trabalho, que incidem diretamente sobre as concepções de currículos ${ }^{4}$.

Trata-se de entender o currículo como um campo ideológico, de reprodução e, ao mesmo tempo, de resistência, em que o entendimento sobre 'o que ensinar' está definitivamente atrelado às relações de poder e à luta por um certo tipo de sociedade. Não há, portanto, idealização possível na leitura sobre a relação entre poder e currículo, ou sobre a hierarquização de conhecimentos nos planos pedagógicos curriculares, traduzida no cotidiano dos processos de formação profissional. Como já indicamos, o currículo é construído no conflito e nas contradições oriundas da construção social e histórica do conhecimento, passando sempre pelas concepções hegemônicas do mundo do trabalho.

A concepção de 'currículo integrado' está presente na década de 1990 e, ainda hoje, nos currículos da formação técnica em saúde. Visando a um menor isolamento possível entre as disciplinas, a idéia do 'currículo integrado' se aproxima das concepções de Bernstein, denominadas 'classificação', pelo autor. Para ele, as questões mais relevantes no campo do currículo são as que abordam as relações estruturais entre os diferentes tipos de conhecimento que o constituem, e os diferentes tipos de organização do currículo estão atrelados a princípios de poder e de controle. Em Bernstein 
(1996), as organizações estruturais do currículo seriam: o 'currículo coleção' e o 'currículo integrado'. O primeiro tem como característica o isolamento entre as diferentes áreas de conhecimento. Já na organização do 'currículo integrado', as áreas de conhecimento não estão isoladas, possibilitando, por exemplo, que o mesmo conceito seja trabalhado por áreas diversas, o que favorece a interdisciplinaridade. O autor chama de 'classificação' o maior ou menor grau de isolamento entre os tipos de conhecimento na organização do currículo: quanto maior o isolamento entre o conhecimento organizado em disciplinas, maior será o grau de classificação. Para o autor, há uma relação de poder também na 'classificação', que dita o que pode ser ou não incluído no currículo e estabelece o nível de isolamento entre as áreas do conhecimento.

Nas Escolas de Formação Técnica do SUS, a fragmentação dos conteúdos é atribuída ao currículo por disciplinas. Documentos produzidos por essas escolas demonstram que a organização curricular por disciplinas é apontada como uma forma indesejável para a articulação entre conhecimentos que devam subsidiar reflexões e ações desenvolvidas por trabalhadores da saúde. Mais ainda, diríamos que há a crença de que a fragmentação dos conteúdos é um efeito inexorável do currículo por disciplinas. Esse entendimento tem sido respaldado por parte da literatura sobre o currículo, como, por exemplo, Santomé (1998), ou ainda por possível interpretação - que não compartilhamos - dos conceitos de Bernstein (1996), que traduzem o currículo por disciplinas como sinônimo do currículo do tipo coleção.

De acordo com Santomé (1998):

“... cada disciplina nos oferece uma imagem particular da realidade, isto é, daquela parte que entra no ângulo de seu objetivo. Do ponto de vista histórico, a tendência à diferenciação do conhecimento em uma multiplicidade de disciplinas autônomas é algo que vem se concretizando desde o início do século XIX, vinculado ao processo de transformação social que ocorria nos países europeus mais desenvolvidos e que necessitava de uma especialização de acordo com a divisão material do processo de produção favorecido pela industrialização. As técnicas e saberes foram se especializando e circunscrevendo âmbitos específicos. Deste modo, surge o conceito de disciplina com um objeto de estudo, marcos conceituais, métodos e procedimento específicos" (Santomé, 1998, p. 56).

Essa afirmação remete ao entendimento de que a divisão dos currículos escolares e da formação profissional em disciplinas específicas, com métodos e objetos distintos, é parte inseparável do processo de urbanização, modernização e divisão do trabalho que dá a forma histórica do capitalismo em expansão. Diante desse processo, uma unidade ideal do conheci- 
mento, em que o todo da vida social e histórica ainda pudesse ser conhecido e analisado sem o recurso às disciplinas separadas, torna-se, mais e mais, uma meta difícil de alcançar no espaço das instituições escolares e de formação profissional. Mas, ao mesmo tempo, de acordo com as novas formas pelas quais o capital organiza a produção e o trabalho assalariado, tal organização, assim como o avanço científico e tecnológico, indicaria o desejo de junção de áreas de conhecimento, assim como de interdisciplinaridade/transdisciplinaridade como formas de organização curricular e de enfoque metodológico 5 .

Na história recente e atual, os novos modelos de produção industrial vão demandar dos sistemas educacionais — mediante flexibilização do mercado de trabalho, estratégias de competitividade, melhoria da qualidade das empresas e mudanças velozes nos desejos dos consumidores, produzidas pela vida administrada - um ajuste às novas maneiras que o capital encontra para administrar suas crises.

Neste sentido, a escola torna-se responsável pela produção de um trabalhador polivalente, com capacidades, 'conhecimentos', valores e atributos, destreza e capacidade de resolver problemas compatíveis com o mundo do trabalho em mutação. Com isso, a educação básica e a educação profissional não podem mais ser negadas aos trabalhadores, pois analfabetos e semi-analfabetos não podem se adaptar às exigências postas pelas novas tecnologias e formas de organização mais exigentes do mundo do trabalho.

Em países de modernização tardia, como o Brasil, isso cria problemas ao processo de acumulação do próprio capitalismo, já que temos uma pesada herança escravista e colonial, seguida de uma tradição elitista, que manteve, e ainda mantém, largas parcelas da população sem a escolaridade mínima. Ou, o que é pior, o processo perverso de modernização mantém à margem milhões de trabalhadores, desempregados, subempregados ou sobrevivendo por meio de atividades diversas, nomeadas pelo eufemismo "economia informal". Inserida nas contradições do cenário atual da nova ordem mundial, a meta é sempre formar trabalhadores "competentes" para o mercado de trabalho (Kuenzer, 1997).

Cabe aqui citar Santomé (1998), que estabelece uma relação entre o currículo por disciplinas e o discurso dos empresários:

“O currículo por Disciplina tem também uma razão organizativa, derivada da forte coincidência que tem ocorrido nos últimos anos nos discursos dos grupos empresariais das sociedades mais industrializadas, em suas queixas contra um sistema educacional que não corresponde às suas necessidades e interesses. Esses discursos inundam nossa sociedade e são rapidamente assimilados por muitos profissionais conservadores e muitas famílias preocupadas com o ameaçador futuro de seus filhos e filhas no âmbito do trabalho. De fato, ocorre muito freqüen- 
temente que na hora de se realizar escolhas entre matérias opcionais ou linhas de trabalho em Disciplinas concretas, façam isso considerando apenas critérios de utilidade e rentabilidade de curto alcance" (Santomé, 1998, p.106).

Ao fazer a relação entre interesses dos empresários e escola, o autor indica um problema de fundo, que poderia ser também referido à sociedade brasileira, sempre posta no caminho de uma ilusória superação do atraso pela via da adesão pragmática às linhas de força dominantes do capitalismo como sistema-mundo. Daí resultam pressões, como as acima indicadas, que passam a exigir das universidades, por exemplo, uma vinculação direta com a esfera da produção, circulação e consumo de mercadorias, quase como se fossem extensões das fábricas, das empresas e do comércio. A criação e a acumulação de conhecimento crítico, com independência e responsabilidade, como trabalho de várias gerações e como parte de um projeto de país que possa sustentar seu crescimento e suas políticas públicas, vão para um segundo plano, e o canto de sereia do pragmatismo mantém o Brasil justamente no atraso que se deseja superar.

No caso da saúde, é notável e marcante o contraste que separa a tradição de medicina pública, voltada para os problemas centrais que afetam a saúde das populações pobres do país, e a medicina mercantil, que torna a saúde física e emocional um item a mais de consumo, uma mercadoria entre outras mercadorias, em centros de compras muito exclusivos, dos quais estão excluídos os pobres e, cada vez mais, grandes parcelas das classes médias urbanas. Diante disso, observa-se a relação existente entre espaços de produção de conhecimento e de ensino, e os interesses do capital. Porém, causa espanto atribuir ao currículo por disciplinas a condição de locus privilegiado para esse feito. Será que as demais modalidades de currículo, na organização capitalista, não sofreriam essa influência?

Continuando a crítica ao modelo disciplinar de currículo, Santomé afirma que argumentações, principalmente oriundas do campo da Sociologia e da Psicologia, ressaltam a necessidade de humanizar o conhecimento com que se entra em contato nas instituições escolares. Neste sentido, diz o autor:

\footnotetext{
“Uma das críticas que vem recebendo a opção disciplinar é a de que em geral realça visões alienadas da sociedade e da realidade. O mundo é apresentado de tal maneira que torna-se difícil captar a importância das intervenções das pessoas em sua formação" (Santomé, op. cit., p. 118).
}

O autor justifica o 'currículo integrado' como uma "força alternativa", jogando a favor de uma educação crítica: 
“Ante as críticas ao modelo de Currículo de disciplinas - enquanto são destacadas as vantagens da pesquisa e do estudo interdisciplinar e a necessidade de adequação às peculiaridades psicológicas dos alunos e alunas - adquire força a alternativa de um 'currículo integrado'. A denominação 'currículo integrado' pode resolver a dicotomia e/ou o debate colocado na hora de optar por uma denominação do Currículo que por sua vez integre os argumentos que procedem da análise e defesa de maiores parcelas de interdisciplinaridade no conhecimento e da mundialização das inter-relações sociais, econômicas e políticas. A opção pedagógica pelo Currículo Integrado é defendida, principalmente, com a conjunção de três grupos de argumentos: com argumentos epistemológicos e metodológicos relacionados com a estrutura substantiva e sintática da ciência; com base em razões psicológicas (razões derivadas do papel da experiência na aprendizagem, e considerações sobre a importância dos processos na aprendizagem); e com argumentos sociológicos" (Santomé, op. cit., pp. 112-113).

Pensar os currículos voltados à formação técnica em saúde significa ter como premissa que as práticas curriculares são marcadas tanto pela historicidade da construção do próprio conhecimento, como pelo pensamento hegemônico no mundo do trabalho. Ou seja, trata-se de um processo conflituoso e contraditório, em que as exigências de uma formação humanista e crítica entram em constante choque com as exigências pragmáticas e objetivas do conhecimento definido pela divisão social do trabalho posta pelo capitalismo, cuja característica central, lembrando aqui Marx, é estar em constante expansão, buscando novos mercados, pesquisando novas tecnologias, rompendo tradições às vezes milenares e criando relações de trabalho que tendem à mudança.

Na formação técnica em saúde, a tentativa de superar o currículo por disciplinas - mediante a crença de que este modelo causa a fragmentação dos conteúdos - levou grande parte das escolas voltadas para a formação dos trabalhadores da saúde a optar pelo 'currículo integrado'. Diante das dificuldades de instituição imediata do 'currículo integrado', essas escolas implementaram uma prática curricular híbrida, cujas características oscilaram entre um currículo baseado em disciplinas e o almejado 'currículo integrado'. Esta organização curricular foi chamada 'currículo correlacionado'.

Esse currículo estabelece relações entre os conceitos, com o objetivo de que as disciplinas se interliguem umas às outras, evitando o isolamento entre elas. Portanto, a organização curricular se dá sob a forma de disciplinas, mas há a preocupação com uma interdisciplinaridade baseada na correlação de conceitos. Como a interdisciplinaridade consiste numa fusão entre disciplinas diferentes que compartilham um mesmo tema e objeto de estudo, há uma interação mínima entre disciplinas diferentes. Santomé (1998) alerta 
que a interdisciplinaridade "é um processo e uma filosofia de trabalho que entram em ação na hora de enfrentar questões que preocupam cada ação social" (p. 65).

A concepção do 'currículo correlacionado', que busca o menor isolamento possível entre as disciplinas, aproxima este estudo das concepções, já mencionadas, de Bernstein6, denominadas pelo autor como 'classificação' e 'enquadramento' (1996). Segundo ele, a relação entre educação e conhecimento é expressa, no âmbito escolar, por meio da pedagogia, da avaliação e do currículo.

Outra questão a destacar é a já mencionada influência positivista, que, com seu teor cientificista, ajuda a engendrar a noção de que determinados conteúdos não são científicos. Diante desse rigor, traduzido em cientificismo nas disciplinas, podem ocorrer a exclusão de conhecimentos ou a orientação para incluí-los nas práticas curriculares escolares mas não como conteúdo principal, instituindo-se, assim, mais uma forma de hierarquização.

A título de exemplo, a ausência de conteúdos disciplinares sobre a saúde como prática educativa prejudica ações voltadas à prevenção e mesmo às ações curativas, como o uso de determinados medicamentos. Além disso, não ajuda os profissionais a entenderem que a ação que desenvolvem é também um trabalho intelectual, o que ajudaria a humanizar tais ações, desenvolvidas de forma mecânica. Não estamos nos referindo a conhecimentos sobre a educação, traduzidos apenas em técnicas pedagógicas, pois estas são uma redução da reflexão filosófica ao nível de uma razão apenas instrumental. Referimo-nos, isto sim, à inserção como conteúdo que os faça refletir sobre o trabalho educativo em saúde, de modo a entenderem a educação e a saúde como práticas sociais articuladas.

\section{Considerações finais}

A busca da melhor maneira de combater a fragmentação do conteúdo não deve se traduzir no aniquilamento do currículo por disciplinas. A fragmentação dos conteúdos está presente na própria construção do conhecimento científico, embora entendamos que nem todo conhecimento científico resulte em fragmentação. Isto quer dizer que essa fragmentação terá que ser enfrentada, em menor ou maior grau, em toda forma de produção ou transmissão do conhecimento.

Refletir sobre as tendências curriculares na formação técnica em saúde deve ter como premissa que a forma ideal de currículo é um processo sempre em construção. Neste debate, não se devem perder de vista questões centrais, como a exacerbação dos conteúdos técnicos em detrimento dos conhecimentos sociais, o fato de esses conhecimentos estarem apartados nos 
currículos e, ainda, a ausência de conhecimentos de determinados conteúdos científicos e éticos.

O debate curricular entre as correntes do pensamento crítico educacional na saúde sobre a maneira mais eficiente de enfrentar a fragmentação do conteúdo tem tido um acréscimo nas questões a serem refletidas, com a legalização das “'pedagogias das competências'. Ao identificar tendências analíticas associadas às competências, Ramos (2001) comenta:

“... o uso da noção de competência deve-se à necessidade de se expressar claramente os objetivos de ensino em termos de condutas práticas observáveis. Essa associação estaria fundada sobre uma homologia entre os objetivos operacionais de formação e os objetivos operacionais de produção, alimentada por uma cultura psicológica denominada pelo behaviorismo de Skinner, apropriada pedagogicamente por Bloom e Mager" (Ramos, 2000, p. 62).

Há tentativas de construir um novo profissionalismo, em que o desenvolvimento da noção de competência, quer na dimensão cognitiva, quer na socioafetiva, deverá dar conta das situações de mudanças de tipo de trabalho, geradas pelo desemprego inerente ao modelo capitalista vigente. Mais uma vez, a educação deve cumprir a função 'adaptativa' e ter uma missão que não poderá cumprir. Seria ilusório imaginar que a área da saúde e seus profissionais de nível médio fiquem fora desse processo.

Neste cenário de adequação dos currículos ao modelo das competências, há o perigo de se perder a discussão acumulada e materializada pelas Escolas Técnicas do SUS no chamado 'currículo correlacionado', que, sem dúvida, é uma forma bastante interessante de vislumbrar a interdisciplinaridade7, na qual as disciplinas conservam seu conteúdo e método, mas inter-relacionam seus conteúdos.

A busca da integração ensino-serviço pode ser reforçada pelo ideário das competências, por sua face menos crítica. Se, por um lado, na formação técnica em saúde é necessária a articulação entre ensino e serviço, por outro, não podemos endossar o quase "senso comum" de que o ensino ministrado nos serviços de saúde tudo pode, não sendo percebidas e entendidas as contradições presentes no cotidiano dos serviços 8 .

É claro que há situações em que as aulas ministradas nos serviços de saúde podem auxiliar no processo de qualificação profissional, quando aliadas a uma abordagem crítica da realidade cotidiana dos serviços, do trabalho em saúde ali desenvolvido. Por exemplo, os acidentes ocupacionais com materiais perfurocortantes são, cada vez mais, uma questão relevante na qualidade dos serviços. Aí se destacam duas situações: o recapeamento e o descarte de agulhas. Na primeira, observa-se a dificuldade do trabalhador em incorporar uma nova atitude (o não recapeamento de agulhas), que con- 
tradiz um ensinamento fundamental de sua formação profissional: o de que o 'cuidado do outro' constitui o objetivo essencial do seu trabalho e, portanto, deverá se sobrepor a sua autoproteção; na segunda, a carência de equipamento adequado de biossegurança acaba por determinar a incorporação rotineira de medidas variadas, de improviso, acarretando a ampliação do risco à saúde no próprio ambiente de trabalho.

Essa experiência pode ser observada de forma privilegiada nos serviços de saúde, o que facilitaria o ensinamento de procedimentos corretos a adotar. Mas o processo educativo deve lidar com o real e o possível, no sentido de não adaptar o conhecimento ao existente. Isto quer dizer que, se o serviço de saúde onde for ministrado o curso apresentar deformações de qualquer tipo em seu processo de trabalho, o ensino poderá reproduzi-las, ainda que isto não seja desejável do ponto de vista da formação profissional. No mesmo sentido, para que o processo educativo enfrente situações deformadas, instituídas no cotidiano ${ }^{9}$ dos serviços de saúde, é preciso ficar claro que, na situação antes mencionada, a falta de equipamentos adequados, que leva ao improviso, conduz, na maioria das vezes, à crítica à gestão dos serviços.

Considerando as relações de poder presentes nos serviços, percebemos que o trabalhador poderia se sentir constrangido, pois o espaço da sala de aula estaria inserido no serviço de saúde que ele quer criticar. Trata-se, neste caso, do risco de reduzir a discussão à presença ou ausência de dado equipamento, o que aumentará a chance de um viés funcionalista, sem discussões acerca dos determinantes das falhas e das relações sociais e políticas postas em cena.

É necessário ressaltar, portanto, que os conhecimentos que ajudem a enfrentar as questões advindas do mundo do trabalho não se restringem ao local onde ele é exercido. Se é verdade que a experiência ensina e consiste num ponto significativo para a aprendizagem, por outro lado, é preciso fazer a crítica da fé incomensurável na experiência cotidiana como um processo que por si só garante a aprendizagem qualificada. Neste movimento, a contradição10 é um conceito central para as análises acerca da relação entre formação profissional e trabalho na saúde, e da cultura institucional presente no cotidiano dos serviços. 
1 Vice-Diretora de Ensino da Escola Politécnica de Saúde Joaquim Venâncio (EP SJV/Fiocruz) e Professora Adjunta da Faculdade de Educação da Baixada Fluminense (FEBF/UERJ). Doutora em Educação pela Pontifícia Universidade Católica de São Paulo (PUC-SP). <ibrasil@fiocruz.br>

2 Acrescentando que o positivismo de Condorcet teria elementos "utópicos", Lowy (1986) o diferencia do de Comte, para quem o pensamento deveria eliminar todo o teor crítico de suas reflexões.

3 Os funcionalistas se diferenciam dos positivistas clássicos, como Comte e Durkheim, ao negarem as leis gerais que regem o funcionamento da sociedade e também ao não compartilharem a visão de que as ciências sociais devem ser reduzidas à descrição de fatos observáveis.

4 Silva (2000) traça um mapa dos estudos sobre currículo. Segundo o autor, “o que ensinar?" constituiu a questão que, a princípio, as teorias do currículo tentaram responder. Concebida nas perspectivas tradicionais como uma questão simplesmente técnica, ela se tornaria mais complexa à medida que as teorias críticas e pós-críticas passaram a conceber o currículo como um campo ético e moral. As perspectivas tradicionais tomavam a resposta à questão "o que ensinar?" como dada e se concentravam na questão de "como ensinar?". Para essas perspectivas tradicionais, 'teorizar o currículo' resumia-se em discutir as melhores e mais eficientes formas de organizá-lo. As teorias críticas iriam contestar esse raciocínio de forma radical. Seu primeiro movimento seria, justamente, questionar o conhecimento corporificado no currículo. Elas, então, perguntavam: "por que este conhecimento faz parte e não outro? Por que alguns conhecimentos são considerados válidos e não outros? Quais são os interesses e as relações de poder que fazem com que determinados conhecimentos acabem fazendo parte do currículo, enquanto outros são excluídos?".

5 Vide, por exemplo, a proposta de áreas de conhecimento em torno do desenvolvimento de competências, nas Diretrizes Curriculares Nacionais do Ensino Médio (Brasil, 1998).

6 Basil Bernstein é um dos autores significativos da denominada Nova Sociologia da Educação, desenvolvida na Inglaterra, a partir da década de 1970. A crítica do currículo, nesse movimento, tinha em vista a Sociologia da Educação tradicional.

7 Dentre as diversas noções de interdisciplinaridade, ressalta-se a de Piaget, que a conceitua como um nível de associação e cooperação entre as disciplinas, provocando intercâmbio, reciprocidade e enriquecimento mútuos.

8 Segundo Heller (1982), a hierarquia e a heterogeneidade no cotidiano coincidem ao engendrarem uma "explicitação normal" da produção e da reprodução, não apenas no campo da produção, mas também no que se refere às formas de "intercâmbio". Ainda segundo a autora, a heterogeneidade e a hierarquização são fundamentais para conseguir uma "explicitação normal" da vida em seu cotidiano.

9 Kosik (1976) chama a atenção para o fato de que os fenômenos se entrelaçam na vida cotidiana e “(...) com sua regularidade, imediatismo e evidência, penetram 
na consciência do indivíduo, assumindo um aspecto independente e natural, constituindo o mundo da pseudoconcreticidade. A ele pertencem: - O mundo dos fenômenos externos, que se desenvolvem à superfície dos processos realmente essenciais; - O mundo do tráfico e da manipulação, isto é, da práxis fetichizada dos homens; - O mundo das representações comuns, que são projeções dos fenômenos externos da consciência dos homens, produto da práxis fetichizada, formas ideológicas do seu movimento e o mundo dos objetos fixados, que dão a impressão de ser condições naturais e não são imediatamente reconhecidos como resultados da atividade social dos homens" (p. 11).

10 Na tradição marxista, o conceito de contradição assume um sentido singular no caso da ação humana. Nas obras econômicas da maturidade de Marx, a contradição é empregada para designar, entre outras coisas: (a) inconsistências lógicas ou anomalias teóricas intradiscursivas; (b) contradições dialéticas históricas; (c) contradições dialéticas estruturais (ou sistêmicas) (Bottomore, 1998).

\section{Referências bibliográficas}

BERNSTEIN, Basil. 1996 Class, codes and control. Londres: Routledge and Kehgan Paul.

BOTTOMORE, Tom. 1988. Dicionário do pensamento marxista. Rio de Janeiro: Jorge Zahar Editor.

BRASIL. 1998. Resolução CEB/CNE no 3, de 26 de junho de 1998. Institui as DCN para o Ensino Médio. Brasília: MEC. Disponível em: <www.mec.gov.br/ sem tec/ensmed/ftp/res0398.doc > Acesso em: 26 jan. 2004.

HELLER, Agnes. 1982. La revolucion de la vida cotidiana. Barcelona: Edições Penínsulas.

KOSIK, Karel. 1976. A dialética do concreto. Rio de Janeiro: Paz e Terra.

KUENZER, Acácia. 1997. Ensino médio e profissional: as políticas do estado neoliberal. São Paulo: Cortez.

LOWY, Michel. 1986. Ciências Sociais e Ideologias. SP: Cortez.
MOREIRA, Antônio Flávio. e SILVA, Tomás Tadeu da (orgs). 1994. Currículo, cultura e sociedade. São Paulo: Cortez.

RAMOS, Marise Nogueira. 2001. A pedagogia das competências: autonomia ou adaptação? São Paulo: Cortez.

SANTOMÉ, Jurjo Torres. 1998. Globalização e interdisciplinaridade: o Currículo Integrado. Porto Alegre: Artes Médicas.

SILVA, Tomás Tadeu da. 2000. Documentos de identidade. Uma introdução às teorias do currículo. Belo Horizonte: $\mathrm{Au}-$ têntica.

VALLE, Lílian do. 1996. Palestra ministrada para o grupo de pesquisa Imaginário e Escola Pública na UERJ, Rio de Janeiro.

WALLERSTEIN, Immanuel. 2001. Capitalismo histórico e civilização capitalista. Rio de Janeiro: Contraponto.

YOUNG, Michael. 1971. Knowledge and control: new directions for the Sociology of education. Londres: Coller-Macmillan. 